\title{
NOTICIÁRIO TECLADO: O SUICÍDIO EM PAUTA NA MÍDIA DIGITAL
}

\author{
Typed News: Suicide In Digital Media Agenda \\ Noticiário Digitado: El Suicidio En Pauta En La Midia Digital
}

Débora Victor Aragão Alves Suely Emilia de Barros SANTOS

\begin{abstract}
Resumo: A pesquisa se propôs a investigar como se mostra a compreensão do suicídio a partir de narrativas de blogs da cidade de Garanhuns e região. Cartografou-se blogs que noticiaram sobre esse tipo de morte, tomando a cartografia clínica como uma via que busca apontar para a experiência do cartógrafo como a principal forma de compreender os atores e cenários que lhe vieram ao encontro. A fenomenologia hermenêutica heideggeriana apareceu como lúmen possível para a aproximação com relação aos fenômenos que foram revelados. Foram selecionadas cinco (5) notícias, dentre as quais quatro (4) são referentes ao ano de 2017 e uma (1), ao ano de 2018. Utilizou-se da "Analítica do Sentido", de Dulce Critelli, como método para trazer os fenômenos à luz, bem como da análise compreensiva, como uma forma de compreendê-los, de modo que a metodologia foi tomada como um caminho que não busca por verdades únicas, ao passo que a concebe como desvelamento. Através da investigação, percebeu-se: a criminalização do suicídio; a exposição do corpo; a espetacularização da morte na contemporaneidade; a vitimização; o olhar que patologiza o fenômeno e a impessoalidade no modo de anunciar "mais um" suicídio.
\end{abstract}

Palavras-chave: Suicídio; Blogs; Fenomenologia Hermenêutica.

\begin{abstract}
The research proposed an investigation on how the comprehension of suicide is shown by narratives of blogs from the city of Garanhuns and its region. Blogs with news about this type of death were cartographed, taking the clinical cartography as a path that looks for to aim the cartographer's experience as the main way of comprehending the actors and scenery that had come to meet. The Heideggerian hermeneutic phenomenology appeared as a possible lumen for the approach related to the phenomena that were revealed. In this direction, five (5) news were selected. Four (4) are regarding to the year of 2017, and one (1) to the year of 2018. It was used the "Analítica do Sentido", from Dulce Critelli, as a method to bring the phenomena to light, as well as the comprehensive analysis, as a means to comprehend them, in a way that the methodology was taken as a path that does not look for unique truths, as conceives it as an unveilment. It was perceived through the investigation: criminalization of suicide; body exposure; spectacularization of death in contemporaneity; victimization; the look that patologizes the phenomenon and the impersonality of anouncing "another" suicide.
\end{abstract}

Keywords: Suicide; Blogs; Hermeneutic Phenomenology.

Resumen: La pesquisa se propuso a investigar como se muestra la comprensión del suicidio desde las narrativas de blogs de la ciudad de Garanhuns y región. Se cartografió blogs que noticiaron acerca del tipo de muerte, tomando la cartografía clínica como vía que busca apuntar para la experiencia del cartógrafo como la principal manera de comprender los actores y escenarios. La fenomenología hermenéutica heideggeriana surgió como posible lumen para la aproximación con relación a los fenómenos que fueron revelados. Fueron seleccionados cinco (5) noticias, entre ellas cuatro (4) que se refieren al año de 2017 e una (1) correspondiente al año de 2018. Se utilizó la "Analítica do Sentido", de Dulce Critelli, como método para sacar los fenómenos a la luz, así como de la análisis comprensiva, como una manera de comprendelos, de manera que la metodología fue tomada como un camino que no está en la búsqueda de verdades únicas, sino que la concibe como desvelamiento. A través de la investigación se averiguó que: la criminalización del suicidio; la exposición del cuerpo; la espectacularidad de la muerte en la contemporaneidad; la victimización; la mirada que polariza el fenómeno y la impersonalidad en la manera de anunciar "más un" suicidio.

Palabras clave: Suicidio; Blogs; Fenomenología Hermeneutica 


\section{Introdução}

O presente estudo, de caráter qualitativo, surgiu a partir da necessidade de refletir e discutir acerca de como se mostra a compreensão do suicídio a partir de narrativas colhidas em blogs ${ }^{1}$ da cidade de Garanhuns - PE e região. Assim, buscou-se desvelar sentido acerca da abordagem midiática virtual do fenômeno, numa perspectiva fenomenológica existencial heideggeriana, compreendendo que o tema se apresenta como uma questão complexa, que não possui causas gerais definidas, sendo colocado, muitas vezes, na esfera do mórbido, sombrio e insalubre.

A pergunta norteadora desta pesquisa se propôs a interrogar a seguinte questão: como se mostra a compreensão do suicídio em narrativas presentes em blogs da cidade de Garanhuns e região? Desse modo, caminhou-se em direção ao desvelamento de sentido, no intuito de investigar como se revela a compreensão do suicídio a partir das narrativas dos participantes-colaboradores da pesquisa. No que se refere aos objetivos específicos, pretendeu-se: cartografar blogs da cidade de Garanhuns - PE e região que tratam sobre o tema; refletir a respeito da contribuição fenomenológica existencial para o fenômeno do suicídio e buscar compreender o lugar do profissional de Psicologia, na perspectiva fenomenológica existencial, diante do suicídio.

Atualmente, as mídias digitais desempenham um papel crucial na sociedade, intervindo de forma marcante na população, em suas crenças, atitudes e modos de ser-no-mundo. Entretanto, inicialmente, questionou-se a relação entre mídia e suicídio a partir da obra Os Sofrimentos do Jovem Werther (1774), de Goethe, que gerou uma implicação do livro a casos de suicídio na Europa, nomeando-se, posteriormente, de "Efeito Werther" a imitação de suicídios (Organização Mundial de Saúde, 2000).

São várias as compreensões sobre a morte e o morrer ao longo da história, porém o tema nunca esteve longe da realidade de nenhuma civilização, assim como o suicídio, que aparece vinculado à temática da morte e diretamente atrelado à finitude humana. Contudo, no que se refere à temática, Silva (2018) aponta que: "À luz do direito, da religião e da ciência é promovida uma interdição do ato de pôr fim à vida, de modo que ele não pode ser encarado como uma possibilidade" (Silva, 2018, p. 12-13).

Nesse sentido, o autor expõe que, historicamente, a compreensão acerca do suicídio esteve atravessada, na maioria das vezes, por tais olhares, de modo que essas concepções constantemente se ligam a julgamentos morais sobre a criminalização do ato, a noção de pecado ou sua patologização. Entretanto, na atual pesquisa, buscou-se o afastamento de tais julgamentos que envolvem o tema, no intuito de compreender o suicídio enquanto fenômeno, que se revela de forma singular à

\footnotetext{
1 Segundo Madeira e Gallucci (2009, p. 2), blogs são “páginas de internet, semelhantes a diários virtuais, mas com diferentes finalidades: pessoais, profissionais, corporativas. Por essa semelhança, são escritos, em geral, na primeira pessoa, expressando opiniões, críticas e ideias de cada internauta ou empresa”.
}

luz do horizonte histórico no qual vivenciamos como contemporaneidade, no sentido de possibilitar reflexões e compreensões outras sobre o ato de pôr fim à vida.

No que se refere ao contexto da cidade de Garanhuns, a temática do suicídio constantemente se revela no cotidiano dos moradores, seja através de conversas corriqueiras, jornais ou redes sociais, o que movimentou a inquietação e investigação, por parte das pesquisadoras, acerca do modo como o assunto é percebido através de blogs da cidade e região.

Em contrapartida, chamou a atenção a forma como no município o tema é pouco discutido de forma aberta e democrática, não possibilitando a participação da comunidade no geral, em momentos que se propõem a debater estratégias de prevenção ao suicídio. Isso se mostra, por exemplo, na burocracia estabelecida para se ter acesso aos dados referentes ao número de óbitos por essa causa de morte no município, que deveriam ser disponibilizados pela Vigilância Epidemiológica de forma acessível à população. Porém, esbarra na necessidade de se estar veiculado à alguma instituição (Universidade, Prefeitura, etc.) para ser possível o acesso, ainda, mediante a apresentação prévia de um ofício como exigência.

Desse modo, a presente pesquisa surgiu no intuito de estabelecer um diálogo democrático com os mais diversos atores sociais a respeito da compreensão do suicídio por parte da mídia digital local, buscando socializar o conhecimento científico de forma abrangente e acessível.

\section{Trilhando Caminhos On-line}

Como possibilidades para caminhar em direção à investigação proposta, nos inclinamos a analisar a seguinte interrogação: como se mostra a compreensão do suicídio a partir de narrativas de blogs da cidade de Garanhuns e região? Logo, buscou-se uma aproximação do fenômeno do suicídio através da pesquisa qualitativa, que, para Silva e Santos (2017, p. 112), tem como foco "[...] compreender questões singulares, lidando com inquietações que não se propõe a ser quantificadas, controladas ou mesmo universalizadas a partir de resultados encontrados", bem como se lançou mão da pesquisa documental, que "[...] caracteriza-se pela busca de informações em documentos que não receberam nenhum tratamento científico, como relatórios, reportagens de jornais, revistas, cartas, filmes, gravações, fotografias, entre outras matérias de divulgações" (Oliveira, como citado em Sá-Silva, Almeida \& Guindani, 2009).

Aliada à pesquisa qualitativa, - que possibilitou olhar às contribuições singulares de cada participante-colaborador, de modo não inclinado a generalizações ou quantificações, mas sim em direção a compreensão dos fenômenos desvelados - a pesquisa documental se mostrou como uma forma de entrar em contato, nesse caso, através do meio virtual, com notícias de blogs da cidade de Garanhuns e região que ainda não foram 
analisadas cientificamente.

Assim sendo, essa pesquisa é resguardada pela Resolução n ${ }^{0}$ 510, de 07 de abril de 2016, Art 1, parágrafo único, ítem III, o qual diz que: "Não serão registradas nem avaliadas pelo sistema CEP/CONEP [...] pesquisa que utilize informações de domínio público [...]" (Conselho Nacional de Saúde, 2016, p. 2).

Desse modo, a pesquisa teve como foco narrativas encontradas online - referentes aos anos de $2017 \mathrm{e}$ 2018, publicadas em blogs da cidade de Garanhuns e região - no intuito de buscar uma aproximação sobre como se mostra a compreensão do suicídio a partir das contribuições relativas a esse tipo de mídia digital.

A cartografia clínica apareceu como possibilidade de entrar em contato com as narrativas em seu contexto virtual, bem como permitiu a afetação através da experiência do encontro com essas. Através dela, o pesquisador delineia os caminhos da pesquisa em seu próprio caminhar, “[...] quando o próprio modo de ser afetado pelas coisas descortina como estas podem ser vislumbradas" (Braga, 2014, p. 122).

Dessa maneira, para Aun e Morato (2009, p. 123), “[...] a cartografia atravessa o tempo, nasce dos movimentos geográficos da terra, acompanha e se faz nas transformações da paisagem, criando história”. Nessa perspectiva, o cartógrafo, marcado por sua própria vivência, aparece como aquele que anuncia a experiência de seu encontro com aquilo que compõe o cenário que investiga. Por isso, a cartografia surgiu como um caminho que possibilitou o acesso à experiência dos participantes-colaboradores desta pesquisa - aqueles que narraram às notícias publicadas nos blogs - e, portanto, a comunicação sobre a experiência acerca do encontro com as narrativas online.

Uma vez que o caminhar no presente estudo se fez rumo à compreensão de sentido, a narrativa, que aparece como a contação da experiência, se mostrou como uma possibilidade viva e vívida de acesso à como o narrador experienciou a realidade na qual viveu, sendo nela onde residem suas afetações. Por sua vez, no que se refere ao narrador, Benjamin (1987) o concebeu como um viajante. Desse modo, é na narrativa que a experiência é transmitida, contada de pessoa para a pessoa, de forma que o narrador marca e é marcado pelos espaços nos quais transita e pelas histórias que escuta. Nessa direção, Benjamin (1987) aponta que a narrativa

[...] é ela própria, num certo sentido, uma forma artesanal de comunicação, ela não está interessada em transmitir o 'puro em si' da coisa narrada como uma informação ou relatório. Ela mergulha a coisa na visão do narrador para em seguida retirá-la dele, assim se imprime na narrativa a marca do narrador, como a mão do oleiro na argila do vaso (p. 205, aspas do autor).

Nesse sentido, é testemunhando a contação da experiência de outros que o ouvinte é capaz de dar novo sentido ao que escuta, imprimindo, também, a marca de sua própria experiência, que põe o que foi vivido em ação, em um constante contar e recontar de histórias. Assim, aqui, a noção de verdade empregada pelas ciências naturais é rompida, de maneira que esta passa a ser compreendida em seu sentido grego (alethéia), ou seja, como desvelamento.

No intuito de lançar um olhar que busca compreender o sentido sobre as narrativas, partiu-se da Analítica do Sentido, de Dulce Critelli (1996), como método de investigação para a análise compreensiva das histórias narradas, visto que,

[...] na análise compreensiva do fenômeno, cabe ao pesquisador não somente reproduzir as narrativas dos colaboradores nem o conhecimento teórico da literatura pesquisada, mas ampliar o seu próprio horizonte para que possa interpenetrar o outro e por ele ser interpenetrado (Silva \& Santos, 2017, p. 121).

De acordo com as autoras, o pesquisador aparece como mensageiro, ou seja, aquele que desvela sentido para então comunicá-lo. Sendo assim, nessa perspectiva, o pesquisador não é guiado pela técnica moderna ou um saber-fazer delimitado a priori, mas sua tarefa é desvelar sentido a partir da hermenêutica - em sua compreensão heideggeriana, que quer dizer "trazer mensagem e dar notícia [...]" (Heidegger, 1959/2011, p. 97).

Desse modo, trabalhou-se com três dos aspectos referentes ao procedimento para compreensão de sentido, como expõe Santos (2016): (1) transcrição das narrativas; (2) literalização das narrativas; e (3) análise de sentido - compreensão do pesquisador diante das narrativas.

Como aponta Santos (2003), a palavra sentido remete ao se projetar, ou seja, se lançar em direção a algo. Logo, para a autora, o projetar-se encaminha para a compreensão de um sentido, em que é imprescindível ressaltar o não estabelecimento de uma verdade única, mas seu caráter de abertura em direção à compreensão sobre determinado fenômeno.

No entanto, tal compreensão, ainda que singular, não se mostra de forma isolada, isso porque, no pensamento de Critelli (1996, p. 67, aspas da autora), “[...] o indivíduo não é jamais um ente 'solipso', mas coexistente”, uma vez que, nessa direção, a coexistência aparece como "[...] o fundamento de toda possibilidade humana de compreender e de todas as suas formas expressas de conhecer, de referir-se ao que é, inclusive a si mesmo" (Critelli, 1996, p. 67, grifos da autora). Dessa maneira, para a autora, inspirada pelo pensamento heideggeriano, a coexistência se mostra como elemento essencial para o movimento de mostração dos entes.

A fim de compreender como os entes se mostram, Critelli (1996) propôs a Analítica do Sentido. Segundo a autora, "[...] não basta os entes estarem aí para serem reais", acrescentando que "[...] tudo só chega à sua 
plena existência, isto é, torna-se real” (Critelli, 1996, p. 15) através de cinco possibilidades de mostração, sendo elas: (1) desvelamento - quando o fenômeno é desocultado; (2) revelação - quando comunica-se sobre o que se foi revelado; (3) testemunho - quando o fenômeno é visto e ouvido por outros; (4) veracização - quando o fenômeno é tomado como verdadeiro publicamente; (5) autenticação - quando o fenômeno é tomado como verdadeiro através da experiência singular e afetiva (Critelli, 1996). Porém, é importante frisar que os movimentos de desvelamento dos fenômenos propostos pela autora não acontecem sequencialmente, não havendo, então, o que acontece primeiro ou depois, podendo estes ocorrer simultaneamente.

Desse modo, no que se refere à pesquisa qualitativa à luz da fenomenologia existencial ao modo de Heidegger, Silva e Santos (2017, p. 112) expõem que, nesse tipo de investigação, busca-se “[...] compreender os fenômenos humanos e as realidades sociais a partir deles mesmos, e não de uma representação imutável, precisa”, contrariando ainda a perspectiva positivista de verdade única e questionando a noção hegemônica de neutralidade, dando ênfase à experiência, uma vez que, nesse modo de pesquisar, “[...] pesquisadores e participantes encontram-se implicados, longe de qualquer perspectiva de neutralidade”, de forma que "[...] os participantes da pesquisa não aparecem como meros sujeitos, mas como colaboradores/co-autores na produção conjunta de reflexões” (Silva \& Santos, 2017, p. 115).

Assim, a pesquisa numa perspectiva fenomenológica existencial heideggeriana se propõe a romper com a noção de método adotada pelas ciências naturais, em que este é utilizado para se chegar a uma única verdade sobre algo, buscando, dessa forma, conceber o método como um "caminho para”, e não "[...] como um caminho seguro que vai sendo traçado com prescrições dadas de antemão” (Silva \& Santos, 2017, p. 113).

\section{Percorrendo Territórios Virtuais: Compreensões Reveladas}

João Gostoso era carregador de feira livre e morava no morro da Babilônia num barracão sem número

Uma noite ele chegou no bar Vinte de Novembro

Bebeu

Cantou

Dançou

Depois se atirou na lagoa Rodrigo de Freitas e morreu afogado

(Bandeira, 1993, p. 136)

Como possibilidade para compreender a questão bússola, isto é: como se mostra a compreensão do suicídio nas narrativas presentes em blogs da cidade de Garanhuns e região?, a análise compreensiva foi tomada como uma via de acesso em direção à compreensão do sentido revelado a partir das narrativas escolhidas.
Sobre esse método em pesquisa fenomenológica existencial, Silva e Santos (2017, p. 119) apontam que, nessa direção, "[...] o pesquisador se coloca como mensageiro: sua missão é desvelar sentido, e comunicá-lo”.

Importa assinalar que, na fenomenologia existencial, a compreensão é tomada como condição própria do ser humano, sendo esta o nosso modo singular de perceber o mundo e os entes que o constitui. Assim, como salientam Silva e Santos (2017, p. 119, aspas das autoras): “[...] a compreensão é 'vivida', existencial”. Nessa vertente, buscou-se o afastamento da noção de verdade adotada pelas ciências naturais - que concebe a verdade como única -, no intuito de aproximar-se da verdade em seu sentido grego, como aletheia. Logo, torna-se imprescindível o diálogo com Pompeia e Sapienza (2004) e sua compreensão sobre verdade como aletheia:

Aletheia é formada por um prefixo de negação (a) e por um radical (lethe), que significa esquecimento. Aletheia pode ser o 'não esquecido'. [...] Não-esquecido pode ser o recordado. Recordar vem do radical latino cor-cordis, que significa coração. Se lermos re-cordar, isso soa como se disséssemos algo assim: colocar o coração de novo; aletheia, verdade - não meramente o não-esquecido, mas aquilo em que se pode pôr de novo o coração. (p. 160-161, grifos dos autores).

Na perspectiva dos autores, a verdade como aletheia é existencial, ou seja, surge como uma verdade vivida. Dessa forma, a verdade aparece como aquilo que se mostra a alguém, num determinado contexto, de modo que nunca se esgota, uma vez que se revela enquanto fenômeno: aparecendo e, ao mesmo tempo, se encobrindo para um dado olhar. Contudo, a respeito do movimento de desvelamento de um fenômeno, Critelli (1996, p. 68) ressalta: "O aparecimento de algo só se torna plenamente efetivado se o que aparece tiver como origem, iluminação, clareira um certo ser-no-mundo, um certo coexistir, cuja função é permitir este aparecer [...]”, ou seja, a autora aponta que o aparecimento de algo está relacionado a um determinado humano percebê-lo, tornando-o real.

Ainda, é importante ressaltar o caráter de singularidade - no que se refere ao olhar do próprio pesquisador a respeito do que se propõe investigar - que advém desse modo de pesquisar. Nessa direção, em diálogo com os participantes-colaboradores deste estudo, foi tomado como foco o modo como o sentido revelado a partir das narrativas afetaram as pesquisadoras.

Dessa maneira, após cartografar diversos blogs da cidade de Garanhuns e região que tratam sobre suicídios que ocorreram na cidade, foram selecionadas cinco notícias, sendo estas referentes aos anos de 2017 e 2018. A partir do encontro com as narrativas, foi possível perceber determinados fenômenos que se iluminaram, como se procurou destacar a seguir. 


\section{1. "Criminalização" do suicídio}

Em uma das notícias analisadas, já em seu título, é inevitável não atentar para o anunciado: “Garanhuns: Homem comete suicídio furando o ouvido com furadeira” (Blog J Campos, 2017, online). Chamou a atenção e, ao mesmo tempo, impactou o fato de, ainda no título da notícia, se retratar o meio pelo qual alguém se matou.

Para a World Health Organization ${ }^{2}$ (WHO), no documento Preventing Suicide $-A$ resource for media professionals, “[...] a frase 'cometeu suicídio' implica criminalidade [...] e desnecessariamente aumenta o estigma vivenciado por aqueles que perderam alguém por suicídio”3 (WHO, 2017, p. 6, aspas do autor, tradução das autoras). Também, no folheto intitulado "Suicídio - Saber, agir e prevenir", do Ministério da Saúde (2017), são feitas sugestões sobre o que fazer e o que não fazer acerca da veiculação de notícias sobre o tema, trazendo a utilização da palavra suicídio no título da notícia como um dos aspectos a serem evitados. Além disso, a WHO (2017) também expõe que a utilização da palavra suicídio no título da notícia deve ser evitada, uma vez que aparece como uma forma de sensacionalismo.

A esse respeito, uma das notícias diz em seu título: "Mais um cidadão praticou suicídio em Garanhuns/ PE” (Blog Jardim do Agreste, 2018, online). Compreendeu-se que o uso da palavra "praticou" carrega o sentido de crime, como consta referenciado acima através da palavra “cometeu”, a partir da contribuição da WHO (2017).

Nessa mesma direção, outra manchete destaca: "Usou a própria pistola: Policial civil comete suicídio na Vila do Quartel em Garanhuns” (V\&C Garanhuns, 2017, online). Então, percebeu-se que a palavra “cometeu" carrega o mesmo sentido de crime, pois remeteu ao ato de pôr algo em prática, assim como na palavra "praticou”, inclusive, passível a repetição, como se existisse uma “categoria suicídio”, tendo este uma única forma de se revelar.

Desse modo, quando se fala que alguém praticou suicídio, entendeu-se como se homem e fenômeno - aquilo que se revela - estivessem dissociados, isto é, como se o suicídio fosse algo que se "colocasse em prática”. Assim, a compreensão dos participantes-colaboradores a esse respeito apareceu como distante da noção existencial heideggeriana, em que o filósofo afirma a indissociabilidade que caracteriza a coexistência homem-mundo. Entretanto, o suicídio, enquanto fenômeno, só pode ser compreendido a partir da clareira em que se revela, ou seja, a partir do próprio homem.

Assim sendo, para melhor vislumbrar a compreensão fenomenológica existencial a respeito da relação entre homem e mundo, recorreu-se a Heidegger (1927/2002, p. 90), quando este esclarece sua compre-

2 Organização Mundial da Saúde, em tradução livre.

3 “The phrase 'comitted suicide' implies criminality (suicide remains as a criminal offense in some countries) an unnecessarily increases the stigma experiencied by those who have lost a person to suicide" (WHO, 2017, p. 6). ensão ontológica a respeito do homem, o qual concebeu como ser-no-mundo, afirmando que a expressão "[...] já em sua cunhagem, mostra que pretende referir-se a um fenômeno de unidade”. Desse modo, homem e mundo aparecem como impossíveis de serem dissociados.

Ainda se referindo ao que chamou de ser-no-mundo, o autor esclarece que a palavra "em" - que remete a noção de ser-em-um-mundo -, em sua origem, deriva de innan-, que quer dizer morar, habitar, em que "an" significa estar acostumado a, habituado a, familiarizado com (Heidegger, 1927/2002). Dessa forma, pode-se compreender o que o filósofo chamou de ser-no-mundo como um existencial que se mostra através de um ente no qual habita um mundo que, desta ou daquela forma, lhe é familiar.

Nessa direção, em diálogo com Dutra e Roehe (2013, p. 112, grifos dos autores), é possível elucidar que: “[...] Pensar nos aspectos existenciais do fenômeno do suicídio implica considerar que qualquer fenômeno humano se origina nas características do modo de ser do homem”. Segundo os autores, o ser humano existe em um movimento de relação com o próprio ser, relação esta que acontece no mundo, através do processo de escolhas diante de seus incontáveis modos de ser. Contudo "[...] morte é a possibilidade mais própria: é de si mesmo para si mesmo” (p. 112). Entretanto, é imprescindível ressaltar que a morte, no pensamento heideggeriano, não se revela como um estágio, algo ao qual se chega, mas a própria vida se constrói enquanto finitude, como o que o filósofo chamou de ser-para-a-morte ${ }^{4}$ (Dutra \& Roehe, 2013).

No entanto, é pertinente ressaltar que se dialogou com os documentos referentes a WHO e ao Ministério da Saúde no sentido de situar o que se compreende como o papel da mídia diante do ato de findar a própria existência por parte de organizações de saúde de referência nas esferas internacional e nacional, respectivamente. Contudo, também é importante salientar o caráter prescritivo e normatizador que atravessa essas formas de buscar prevenir o suicídio, ligadas a uma perspectiva moralizante de se enxergar o fenômeno, uma vez que o expõe como algo que pode e deve ser evitado. Ainda, é relevante pontuar que, na ação do profissional de Psicologia, é fundamental caminhar na contramão da norma vigente, própria das ciências naturais, que se apresenta de modo a buscar generalizar e quantificar os fenômenos.

Em diálogo com Silva (2018), a respeito da criminalização do suicídio, a autora esclarece:

Em primeiro lugar, a noção do direito à vida presente na época em que vivemos, materializada no artigo $3^{\circ}$ da Declaração Universal dos Direitos Humanos, promoveu um deslocamento na noção de vida, em que ela passa a ser tomada como um

4 "A morte é a possibilidade mais própria da pre-sença. O ser para essa possibilidade abre à presença o seu poder-ser mais próprio, em que está sempre em jogo o próprio ser da pre-sença” (Heidegger, 1927/2001, p. 47, grifos do autor). 
bem supremo, inalienável, ou ainda, indisponível, nos termos da doutrina jurídica, ou seja, entendido como aquilo de que não se pode dispor ou renunciar. Nesse sentido, a própria noção de direito é obscurecida, tornando a vida um dever... Sob esse prisma o suicídio é tomado como crime, pois promove um atentado contra a vida. (p. 10-11).

Desse modo, ao passo que concebemos a vida como um bem supremo, que deve ser preservado a qualquer custo, o suicídio passa a ocupar o lugar da transgressão. Assim, o ato, percebido enquanto crime, revela um modo regulador e normatizador, percebido como advindo de uma forma de pensar, característica do nosso tempo, que calcula ${ }^{5}$. Embora o suicídio nunca tenha sido de fato criminalizado no Brasil, foi tomado enquanto crime em diversos países ${ }^{6}$.

Nessa direção, percebeu-se que a utilização das palavras "cometeu" e "praticou”, que aparecem nas notícias acima destacadas, carregam a noção de crime atribuída ao suicídio, evidenciando o ainda presente estigma associado à atitude de pôr fim à própria vida.

\subsection{Exposição do corpo}

Entre as notícias analisadas, também foi possível perceber a exposição do corpo daquele que tirou a própria vida, seja através de fotos ou da contação detalhada do cenário que compôs a morte. Nesse sentido, os participantes-colaboradores narraram que:

O suicídio de um homem chocou os moradores de Garanhuns, Agreste de Pernambuco, na tarde desta quinta-feira (10) (Blog J Campos, online).

[...] estava em casa [...], bairro São José, quando pegou uma furadeira de impacto, foi para o quarto, colocou uma broca, ligou a máquina e perfurou o ouvido atingindo o cérebro (Blog J Campos, 2017, online).

De acordo com informações iniciais, ele teria se trancado no quarto, colocado o cano da pistola abaixo do queixo e disparado. A bala transfixou a cabeça e o agente teve morte instantânea (V\&C Garanhuns, 2017, online).

De acordo com as primeiras informações o jovem que foi identificado como sendo [...], de apenas 17 anos teria tirando sua própria vida por meio de enforcamento [...] (Portal Agreste em Alerta, 2017, online).

Utilizando um cinto a vítima [...], 50 anos, que residia no local enforcou-se no banheiro de casa (Blog Colinas News, 2017, online).

\footnotetext{
5 De acordo Queiroz (2018, p. 206), o pensamento calculante é “. . . aquele em que se toma a razão como suficiente e a previsão e o controle a partir do cálculo como verdades últimas”. Assim, o pensamento calculante propõe a produção de resultados, em que estes são tomados como verdades sobre determinado fenômeno.

6 O suicídio era compreendido como autoassassinato, tendo como pena a apreensão de bens, bem como a não permissão do sepultamento do corpo do suicida, sendo a Inglaterra o último país a descriminalizar o ato de pôr fim à vida, em 1961 (Silva, 2018).
}

Um morador [...], em Garanhuns foi encontrado morto na tarde desta quarta-feira (31/1) por meio de enforcamento, em uma arvore [...]. (Blog Jardim do Agreste, 2018, online).

Desse modo, foi revelado que, nas notícias, se procurou descrever o cenário da morte em seus detalhes, como se apontasse um passo a passo para um suicídio. No entanto, as narrativas também desvelaram uma compreensão mórbida do fenômeno, no que se refere à exposição acerca do método utilizado por aquele que decidiu pôr fim à própria vida, o que pode se mostrar como uma tentativa de impactar o leitor.

Tanto a WHO (2017) quanto o Ministério da Saúde (2017) alertam para a não divulgação do método utilizado em um suicídio, de modo que esse último esclarece: “[...] evite mencionar e, principalmente, descrever o método utilizado em um suicídio ou tentativa” (p. 3). De acordo com a referida organização, a descrição detalhada, assim como a discussão sobre a forma como ocorreu o ato, deve ser evitada, uma vez que pode-se contribuir para que uma pessoa vulnerável reproduza o ato ${ }^{7}$.

Nesse sentido, Queiroz (2018) coloca em questão tal perspectiva (2017), suscitando a seguinte reflexão:

Na contemporaneidade, em que a técnica se torna a principal via de apreensão dos fenômenos e comportamentos humanos, ganham força às práticas preventivas apoiadas nas noções de grupos vulneráveis, escalas de risco e intervenções previamente consideradas adequadas para as situações de suicídio, procedimentos que buscam garantir que o ato não seja executado (p. 209-210).

Desse modo, tal noção aparece ligada ao pensamento de que o suicídio pode ser evitado, desde que possamos nos antecipar ao ato, isto é, controlá-lo. Contudo, como esclarece a referenciada autora: "Ao limitarmos previamente a forma de ver o fenômeno, podemos ofuscá-lo” (Queiroz, 2018, p. 209).

\subsection{Espetacularização da Morte na Contemporaneidade}

Dentre quatro das notícias analisadas, expôs-se explicitamente o rosto daquele que decidiu pôr fim à própria vida. Diante desses fatos observados, pareceu que o intuito era o de chocar, como uma das narrativas supracitadas menciona: "O suicídio de um homem chocou os moradores de Garanhuns [...]” (Blog J Campos, 2017, online). Entretanto, ao mesmo tempo, apareceu como uma forma de atrair a atenção do leitor.

Sobre o uso de imagens que fazem referência à morte de alguém, no âmbito virtual, Luz e Moraes (2016, p. 3) afirmam: “[...] a fotografia confere status, vira objeto de ostentação, sempre com foco no outro, em impressioná-lo”. Desse modo, foi revelado que o rosto daquele que decidiu se retirar da vida é mostrado, também, para que um outro o perceba, em forma

\footnotetext{
7 "Detailed description and/or discussion of the method should be avoided because this will increase the likelihood that a vulnerable person will copy the act” (World Health Organization, 2017, p. 6).
} 
de imagem, o que apontou para um movimento de se evidenciar a morte de maneira que esta se apresenta como a morte do outro, ou seja, como algo alheio a si mesmo.

A esse respeito, em diálogo com Beirão (1992), a autora nos indica um caminho possível para se compreender esse contexto:

Já nos separamos do que está aí, nos instrumentalizamos, e agora vamos lá, como espectadores, analisando, discriminando, observando com a perspicácia da racionalidade. Inevitável usar esse poder nos momentos críticos. O medo da crise, da separação do contexto harmônico, do rompimento com uma acomodação que pode até rolar no esquecimento. Esquecimento da própria finitude (p. 78).

Dessa forma, aquele que se mata rompe com a ordem hegemônica de preservação da vida e anuncia a morte como experiência da finitude humana - que se revela enquanto destino do homem pensado por Heidegger, quando este compreende o ser-para-a-morte como um de seus existenciais. Entretanto, na contemporaneidade, ao passo que se procura afastar a morte do próprio cotidiano, esta também se revela a todo instante como possibilidade última e inevitável, uma vez que a morte do outro retira do encoberto aquilo que buscamos nos desvencilhar: a nossa própria morte.

Acerca da espetacularização da morte na contemporaneidade, as referidas autoras apontam que "[...]. ver na contemporaneidade é tudo, não importa, precisamos do visível, só existe o que é publicado e exposto, o que está ali em nossa tela, aos nossos olhos, o show da vida em questão, da vida dos outros" (Luz \& Moraes, 2016, p. 2).

No que concerne à publicação de notícias sobre suicídio em blogs, se torna ainda mais acessível o alcance a esse tipo de conteúdo e a interação entre os usuários, bem como o compartilhamento da informação de forma rápida. Ainda, se tratando de um ambiente virtual, o apelo visual, ao qual Luz e Moraes (2015) se referem, aparece de forma marcante, de modo que a exposição daquele que finda a própria existência é feita explicitamente, como se em uma espécie de show da vida dos outros, em alusão a afirmação das autoras supracitadas.

A respeito do horizonte histórico que nos constitui contemporaneamente, este "[...] revela um cenário em que a tecnologia, as produções de conhecimento e o mundo virtual fazem morada e determinam o modo de ser humano" (Dutra, 2018, p. 111). Nesse sentido, a referida autora ressalta o que chamou de "midiatização do real".

Nas TV’s, sites e blogues jornalísticos e também pessoais, tudo se transforma em espetáculo de mídia e, ao mesmo tempo, se banaliza. Não é incomum assistir em noticiários da TV e tam- bém em redes sociais, notícias de homicídios, suicídios [...] Ao mesmo tempo, parecem banais, pela frequência com que acontecem e a rapidez com que são substituídos por outras notícias (Dutra, 2018, p. 110).

Desse modo, lançar um olhar fenomenológico existencial sobre o fenômeno do suicídio, ao mesmo tempo, implica situá-lo no horizonte histórico em que este se mostra, compreendendo que o homem existe enquanto ser-no-mundo, o que evidencia a indissociabilidade entre homem e mundo.

\subsection{Vitimização: um apelo à crimina- lização?}

A palavra vítima aparece em quatro das cinco notícias analisadas, o que apontou para a necessidade de se voltar à etimologia da palavra. Vítima, do latim vicť$m a$, se refere a "[...]. pessoa contra quem se comete um crime" (Michaelis, 2018). Desse modo, a compreensão de vítima a respeito daquele que decide pôr fim à própria vida apareceu como diretamente atrelada à perspectiva de criminalidade que atravessa as narrativas.

Nas narrativas dos participantes-colaboradores da pesquisa, a palavra "vítima" foi utilizada diversas vezes, como quando foi relatado que, na casa estava a vítima, a mãe e um irmão [...]. (Blog J Campos, 2017, online).

O corpo da vítima foi encontrado pela mãe e pelo irmão, os quais residiam junto com a vítima (Blog Colinas News, 2017, online).

A vítima foi encontrado pela mãe na sala da residência onde morava com a família [...] (Portal Agreste em Alerta, 2017, online).

A utilização da palavra "vítima” foi tomada como uma forma policialesca de compreender o fenômeno, de modo que a maneira como cada história é narrada logo remeteu às páginas policiais. Sobre a forma de compreender aquele que tira a própria vida enquanto vítima, Lessa (2018, p. 109), fazendo alusão ao estudo de Durkheim acerca do suicídio, nos revela o que se pôde perceber como a herança do sociólogo ao nosso tempo, no que se refere a sua definição sobre o suicídio, quando este concebe aquele que finda a própria vida como

[...] uma vítima, ou seja, que sofreu algum mal, imprimindo assim a ideia de um ato lesivo e prejudicial. O desejo de morrer vai de encontro às determinações hegemônicas de preservação da vida e, portanto, deve ser evitado. [...] Evidencia-se aí que o suicídio é uma pedra que interrompe o caminho indicado pelo poder hegemônico, que preconiza a ordem e a vida acima de qualquer coisa.

Nesse sentido, a autora afirma que tal concepção 
acerca do fenômeno carrega um sentido moralizante, fazendo uma leitura do que seria a moral enquanto norma, que parte de uma ideia hegemônica a respeito de algo. Portanto, Lessa (2018) expõe que o ato de findar a própria vida é inscrito tanto no âmbito do senso comum quanto no científico através de pressupostos normativos e prescritivos, que buscam indicar um "como deve ser", deixando de levar em consideração o "poder ser", isto é, não buscando compreender a experiência das pessoas que tentam tirar a própria vida, assim como não percebendo o suicídio como uma possibilidade da ordem do acontecimento no existir humano.

\subsection{Olhando o Suicídio pela Patolo- gização}

Em duas das narrativas que compuseram a atual pesquisa, colocou-se em evidência o lugar do adoecimento como diretamente relacionada ao fenômeno do suicídio:

[...] vinha apresentando um quadro depressivo (Blog Colinas News, 2017, online).

[...] apresentava sintomas de depressão [...] (V\&C Garanhuns, 2017, online).

Desse modo, é pertinente salientar a contribuição crítica de Lessa (2018), ao ressaltar que o fenômeno do suicídio geralmente encontra-se sob a tutela ora de juízes, ora da igreja ou do domínio médico. Em relação a este último, a autora destaca que o suicídio é percebido diretamente enquanto uma manifestação de ordem patológica:

Paulatinamente, o diabo e os juízes foram abrindo espaço para os legisladores da saúde os médicos -, que foram atribuindo ao suicídio explicações somáticas e psíquicas, confiscando a tutela das vidas daqueles que tentavam o suicídio. Nesse sentido, a interdição pelo crime e pelo pecado deu lugar a outro tipo de penhora: a doença. (Lessa, 2018, p. 127).

Colocado no âmbito da patologia, o suicídio passou, progressivamente, a ser tutelado pela ciência médica, que logo procurou atribuir-lhe interpretações somáticas e psíquicas. Na perspectiva das ciências naturais, em que vige uma forma normativa de se conceber a saúde, o fenômeno de finalizar a própria existência passou a compor o lugar do patológico, devendo "[...] ser a todo custo evitado e submetido aos procedimentos corretivos, a fim de se alcançar o estado de saúde, de normalidade e de adaptabilidade" (Lessa, 2018, p. 112). Assim, o ato de pôr fim à própria vida passou a ser encarado como algo patológico, negativo ou inadequado, ou seja, aquilo que deve ser, acima de tudo, evitado.

Desse modo, Feijoo (2018) sinaliza que, na forma causal, própria das ciências naturais, de pensar o suicídio - e marcante no pensamento que atravessa a contemporaneidade - vige a noção de que uma vez que descobrimos as causas de determinado fenômeno, podemos, então, controlar e nos antecipar aos seus efeitos. Contudo, ao mesmo tempo, nos afastamos da compreensão de como o fenômeno de pôr fim à vida acontece, isto é, deixamos de acompanhá-lo em seu próprio desvelar.

\subsection{Impessoalidades no Modo de Anunciar "Mais Um"}

Mais um suicídio foi registrado na cidade de

Garanhuns, nesta quarta-feira 27 de dezembro de 2017 (Portal Agreste em Alerta, 2017, online). Mais um cidadão praticou suicídio em Gara-

nhuns/PE

(Blog Jardim do Agreste, 2018, online).

As narrativas acima suscitaram pensar, a partir da expressão "mais um", que o fenômeno do suicídio se mostra como algo que os moradores da cidade de Garanhuns já possuem alguma familiaridade. Desse modo, no intuito de compreender o sentido revelado, tornou-se imprescindível a contribuição de Heidegger (1927/2001), quando ele se refere ao ser-para-a-morte e a cotidianidade, que estão em jogo na experiência de ser humano. Assim, o filósofo afirma:

A public-idade da convivência cotidiana 'conhece' a morte como uma ocorrência que sempre vem ao encontro, ou seja, como 'casos de morte'. Esse ou aquele, próximo ou distante, 'morre'. Desconhecidos 'morrem' dia a dia, hora a hora. 'A morte' vem ao encontro como um acontecimento conhecido, que ocorre dentro do mundo (p. 35).

Dessa maneira, percebeu-se uma aproximação entre o que Heidegger (1927/2001) chamou de "casos de morte" e o que os participantes-colaboradores nomearam de "mais um suicídio". Na análise heideggeriana, a compreensão da expressão "casos de morte" está atrelada ao modo impessoal que o ser humano vive na cotidianidade, em que "morre-se", como se a morte não fosse um constituinte da própria experiência de existir de cada um.

Novamente, o diálogo com o filósofo se faz necessário, assim como a sua contribuição a respeito do fenômeno da morte:

O 'morre-se' divulga a opinião de que a morte atinge, por assim dizer, o impessoal. A interpretação pública diz: 'morre-se' porque, com isso, qualquer um outro e o próprio impessoal podem dizer com convicção: mas eu não; pois esse impessoal é o ninguém. [...] A morte que é sempre minha, de forma essencial e insubstituível, converte-se num acontecimento público, que vem ao encontro no impessoal. 
O discurso assim caracterizado fala da morte como um 'caso' que permanentemente ocorre. Ele propaga a morte como algo 'real' mas lhe encobre o caráter de possibilidade e os momentos que lhe pertencem de irremissibilidade e insuperabilidade. (Heidegger, 1927/2001, p. 35, grifo e aspas do autor).

Nesse sentido, compreendeu-se que a familiaridade com o fenômeno do suicídio, na cidade de Garanhuns, revelada nas narrativas em frases como "mais um suicídio”, também aponta para um distanciamento em relação à própria experiência de finitude. Como acima destacado, a morte aparece como algo "real", mas, ao mesmo tempo, a atitude de a tratar de modo impessoal, como "mais uma", em que se refere à morte do outro como algo alheio a si mesmo, também parece mostrar o encobrimento do fenômeno enquanto uma possibilidade existencial.

\section{Considerações finais}

No livro Na presença do sentido: uma aproximação fenomenológica a questões existenciais básicas, de Pompeia e Sapienza (2004), os autores trazem três modos de compreensão para a palavra desfecho que chamaram bastante a atenção, no sentido de possibilitar lançar outro olhar para os "finais" que atravessam nossas vidas. Dentre as compreensões possíveis para a palavra, estão: (1) encerramento de um ciclo: o desfecho aparece como final, bem como o preenchimento de algo que ainda precisava ser investigado, porém não qualquer final, mas uma forma marcante deste se apresentar, diretamente atrelada à história como um todo; (2): ação: aqui, o desfecho aparece como o momento em que algo que estava preparado para acontecer se realiza; (3): abertura: o desfecho, ao passo que encerra algo, também é abertura a outras possibilidades.

Ao longo de toda a pesquisa, as narrativas angustiaram, causaram revolta, raiva, mas, ao mesmo tempo, proporcionaram a reflexão a respeito do modo de compreender o fenômeno do suicídio na cidade de Garanhuns - PE. As afetações que foram suscitadas a partir das narrativas possibilitaram a compreensão do tema não apenas a partir do próprio olhar das pesquisadoras, mas através da fusão de horizontes compreensivos: pesquisadoras e participantes-colaboradores da pesquisa.

Cardona (2016, p. 56) nos diz que cada pessoa significa um horizonte, e que "[...] a interação entre as pessoas, sua humanização mediante o diálogo, leva à fusão de horizontes”. Desse modo, a autora mostra a contribuição gadameriana sobre o sentido de compreensão, no qual implica acordo. Entretanto, para Gadamer (2003), o acordo, que surge na conversação, possibilita a elaboração de uma linguagem comum para o diálogo, de modo que este aparece não como "[...] uma mera representação e impor o próprio ponto de vista, mas uma transformação rumo ao comum, de onde já não se continua sendo o que se era” (Gadamer, 2003, p. 555), isto é, quando se é marcado e "tatuado" através do encontro com outros. Assim, segundo a autora, para que se possa compreender, é necessário um “[...] desejo de saber o que o outro quer dizer [...] de compreender-nos a partir e pelo outro" (Cardona, 2016, p. 56), ou seja, de deixar-se afetar.

Logo, a partir do encontro com as narrativas, revelou-se o olhar que criminaliza o ato de findar a própria vida, ainda que esse nunca tenha sido considerado crime no Brasil, assim como também não foi possível deixar de se impactar pela exposição - através de imagens - daqueles que se suicidaram. Também, compreendeu-se que essa exposição diz de um modo de transformar a morte em uma espécie de "show", caracteristicamente presente na contemporaneidade, como apontam Luz e Moraes (2016, p. 2): “[...] o show da vida em questão, da vida dos outros”. Dessa maneira, ali, do outro lado da tela, nos deparamos com a morte, como espectadores; a morte do outro, numa espécie de espetáculo.

Nessa direção, as narrativas também revelaram uma compreensão acerca do suicídio enquanto um fenômeno que aparece atrelado a algum transtorno mental, o que é contado nas narrativas em frases como: "[...] vinha apresentando um quadro depressivo (Blog Colinas News, 2017, online) ou "[...] apresentava sintomas de depressão [...]" (V\&C Garanhuns, 2017, online). Entretanto, a temática do suicídio parece fazer parte do cotidiano dos moradores da cidade de Garanhuns, de forma que as palavras "mais um suicídio" chamaram a atenção em algumas narrativas, revelando certa familiaridade por parte daqueles que residem na cidade em relação ao assunto.

É possível perceber, ao longo da história, que, no fim da Idade Média, o poder médico passou a ascender, ocupando o lugar de controle social que outrora esteve reservado à Igreja. Assim, foram os médicos que então passam a arbitrar sobre a negatividade que envolve o ato de pôr fim a vida. Dessa forma, o suicídio é retirado do lugar de pecado e passa a ser compreendido como um ato de loucura (Conselho Federal de Psicologia, 2013).

Feijoo (2018) sinaliza que, na mídia, bem como na literatura científica, podemos observar a presença de elementos moralizantes a respeito do suicídio em que este é concebido enquanto atravessado pelas noções de crime, pecado, violência e/ou transtorno mental -, de modo que a autora enfatiza a importância de se assumir uma atitude que não naturalize o ato, para que, assim, possamos “[...] ganhar distância dos preconceitos que circundam o fenômeno, para poder, então, aproximarmo-nos da experiência daqueles que passaram por tentativas de finalizar a sua vida” (p. 77).

No que se refere à contemporaneidade, a Internet aparece como um recurso que reconfigura a forma de se conceber a comunicação, tendo em vista que os novos meios de comunicabilidade fomentaram a quantidade de produção de conteúdos independentes (Luz \& Moraes, 2016). Entretanto, ainda que exista uma es- 
pécie de "acordo de cavalheiros" (Barbosa, Ogasawara, \& Benazzi, 2010) por parte dos jornalistas a respeito de não se noticiar casos de suicídio, é nítido que tais acordos tendem a se reconfigurar no âmbito virtual, uma vez que não é necessário ser jornalista para que se publique em um blog, tornando ainda mais complexo e desafiador se estabelecer normas ou diretrizes para a veiculação de notícias sobre suicídio nesse contexto.

Nessa direção, é possível compreender que a publicação ou não de notícias sobre o tema passa muito mais pela abertura dos profissionais em propor um debate acerca do tema, do que de fato por alguma proibição. Assim, evidencia-se a urgência da discussão sobre suicídio e sua cobertura midiática, de modo que os próprios profissionais possam se mobilizar a colocar em questão suas práticas e convenções.

Diante disso, percebeu-se que se faz imprescindível a continuidade da reflexão e do debate a respeito da temática e de como esta pode se mostrar através do horizonte histórico que nos constitui. Por sua vez, compreendeu-se que as ressonâncias da mídia e como esta lida com o tema, principalmente no que se refere a sua forma virtual, marcante em nosso tempo, trazem importantes contribuições para a Psicologia enquanto ciência e aos profissionais que a exercem, podendo ser ainda mais amplamente exploradas em pesquisas posteriores.

Assim, podemos dizer que, à luz da fenomenologia existencial, é possível compreender a ação clínica do psicólogo como voltada para o acontecer do próprio fenômeno, que diz de um movimento de aguardar sereno, em que não se busca prever ou se antecipar aos acontecimentos, mas os acompanha. Sobre isso, Feijoo (2018) propõe olhar a prevenção do suicídio

[...] em seu caráter de acolhimento, ou seja, abrindo um espaço de escuta compreensiva àquele que diz querer pôr fim a sua vida. Acreditamos que desta forma podemos deixar o outro totalmente livre para falar de suas intenções, sem estigmas, preconceitos ou estereotipias (p. 88).

Em contrapartida, a referida autora nos faz uma pergunta desafiadora, porém de imprescindível reflexão: "[...] como encontrar um caminho clínico para pensar a questão do suicídio sem recair nas instruções de um manual, mas também não ficar na indiferença?" (p. 174). A atual pesquisa também não trouxe respostas, mas pôde revelar inquietações e apresentar possíveis compreensões.

Ainda em diálogo com a referida autora, tornou-se possível refletir sobre um modo de cuidado voltado para acompanhar, em seu próprio caminhar, aquele que deseja findar a própria vida, em que nos dispomos, enquanto psicólogos, a lançar mão de uma escuta atenta, que possibilita a abertura para o acolhimento daquilo que é narrado. Assim, a ação clínica do profissional de Psicologia, na perspectiva fenomenológica existencial, aparece "[...] como um modo de estar junto ao paciente, que dá abertura para libertar-se na direção de suas próprias possibilidades de ser, as quais se apresentam ao dialogar e tematizar a sua experiência" (Barreto, Leite, \& Silva, 2015, p. 84-85).

Diante disso, abre-se espaço a outras inquietações: é possível a ação clínica do psicólogo, em situações de suicídio, também se revelar no espaço virtual? De que formas o profissional de Psicologia pode estar junto, inclusive no âmbito virtual, àquele que deseja findar a própria vida?

Nesse sentido, este estudo se encerra enquanto desfecho. Logo, assim como no início do artigo, o diálogo com Pompeia e Sapienza (2004, p. 52) se faz essencial: "[...] É como se o desfecho tivesse de preencher alguma coisa que antes precisasse ser cavoucada". Nesse sentido, o suicídio aparece como um fenômeno que ainda precisa ser profundamente cavoucado, viabilizando um diálogo cada vez mais abrangente e fomentador de discussões.

\section{Referências}

Aun, H. A., \& Morato, H. T. P. (2009). Atenção psicológica em instituição: plantão psicológico como cartografia clínica. In A. P. Nunes, C. L. B. T. Barreto, \& H. T. P. Morato (Coord.), Aconselhamento psicológico numa perspectiva fenomenológica existencial: uma introdução (pp. 121138). Rio de Janeiro: Guanabara Koogan.

Bandeira, M. (1993). Estrela da vida inteira. Rio de Janeiro: Nova Fronteira.

Barbosa, A. C., Ogasawara, R., \& Benazzi, L. A. (2010). Jornalismo e Suicídio: ética e noticiabilidade, 11. Recuperado em 29 de agosto de $2018 \mathrm{de} \mathrm{http://www.intercom.org.br/papers/na-}$ cionais/2010/resumos/R5-3072-1.pdf.

Barreto, C., Leite, D., \& Silva, E. (2015). A ação clínica e a era da técnica moderna: uma compreensão fenomenológica existencial da prática psicológica. Perspectivas em Psicologia, 19(1). Recuperado em Junho de 2018, de http://www. seer.ufu.br/index.php/perspectivasempsicologia/article/viewFile/30361/1658.

Beirão, M. F. S. F. (1992). Existência: um lugar de sentido ou experiência do absurdo? O suicídio. In M. F. S. F. Beirão, \& E. O. de Castro (Orgs.), Morte, vida e destino (pp. 73-82). São Paulo: Companhia Ilimitada.

Benjamin, W. (1987). O narrador, considerações sobre a obra de Nikolai Leskov. In Benjamin, W. Brasiliense (Ed.), Magia e técnica, arte e política (pp. 197-221). Recuperado em Junho de 2018, de https://monoskop.org/images/3/32/ Benjamin_Walter_Obras_escolhidas_1.pdf. 
Blog Colinas News. (2017, Junho 30). Em Garanhuns/PE mulher comete suicídio. Recuperado em Setembro de 2018, de http://blogcolinasnews.blogspot.com/2017/06/em-garanhunspe-mulher-comete-suicidio.html.

Blog do J Campos. (2017, Agosto 11). Garanhuns: homem comete suicídio furando o ouvido com furadeira. Recuperado em Setembro de 2018 de http://blogjcampos.blogspot.com/2017/08/garanhuns-homem-comete-suicidio furando.html.

Blog Jardim do Agreste. (2018, Fevereiro 1). Mais um cidadão praticou suicídio em Garanhuns/PE. Recuperado em Setembro de 2018, de http:// jardimdoagreste.com.br/2018/02/01/mais-um-cidadao-praticou-suicidio-em-garanhuns-pe/.

Braga, T. (2014). Atenção psicológica e cenários sociais: ação clínica, instituições e políticas públicas na promoção da cidadania. Curitiba: Juruá.

Cardona, T. A. (2016). O diálogo: fusão de horizontes: para uma fundamentação gadameriana da antropologia pedagógica. Conjectura: Filosofia e Educação, 21, 46-62. Recuperado em 16 de outubro de 2018, de www.ucs.br/etc/revistas/index.php/ conjectura/article/download/3916/pdf_537.

Conselho Federal de Psicologia. (2013). Suicídio e os desafios para a Psicologia. Brasília: CFP. [Online]. Recuperado de https://site.cfp.org.br/wp-content/uploads/2013/12/Suicidio-FINAL-revisao61.pdf.

Conselho Nacional de Saúde. (2016). Resolução No 510, de 07 de abril de 2016. [Online]. Recuperado em Julho, 2018 de http://conselho.saude. gov.br/resolucoes/2016/Reso510.pdf.

Critelli, D. (1996). Analítica do sentido: uma aproximação e interpretação do real de orientação fenomenológica. São Paulo: EDUC: Brasiliense.

Dutra, E. (2018). Suicídio e Desassossego: pensamentos sobre a morte voluntária em tempos de técnicas. In E. M. do. S. Dutra (Org.), O desassossego humano na contemporaneidade (pp. 103-127). Rio de Janeiro: Via Verita.

Dutra, E. M. do S., \& Roehe M. V. (2013). Suicídio de agricultores no Rio Grande do Norte: compreensão fenomenológica preliminar dos aspectos existenciais. Psicologia em Revista, 19(1), pp. 108-118.

Feijoo, A. (2018). Uma Análise Crítica dos Estudos Fenomenológicos Sobre Suicídio. In A. M. C. L. de Feijoo (Org.). Suicídio: entre o morrer e o viver (pp. 67-104). Rio de Janeiro: IFEN.

Gadamer, H. (2003). Verdade e método: traços fun- damentais de uma hermenêutica filosófica. Recuperado em Outubro de 2018, de https:// edisciplinas.usp.br/pluginfile.php/2442370/ mod_resource/content/1/VerdadeEM\%C3\%A9todo.pdf. Petrópolis: Vozes.

Heidegger, M. (1927). Ser e Tempo. 11. ed. Petrópolis: Vozes, 2002.

Heidegger, M. (1927). Ser e Tempo. 8. ed. Petrópolis: Vozes, 2001.

Heidegger, M. (1959). O caminho da linguagem. (5 ed). (M. S. C. Schuback, trad.). Petrópolis, RJ: Vozes; Bragança Paulista: SP: Editora Universitária São Francisco, 2011.

Lessa, M. (2018). Um estudo sobre a moralização do suicídio. In A. M. L. C. de Feijoo (Org.). Suicídio: entre o morrer e o viver (pp. 105-144). Rio de Janeiro: IFEN.

Luz, E. M. S., \& Moraes, H. J. P. (2016). Espetacularização e Morte nas Redes Sociais. Criar Educação, $O(0)$. Recuperado em Agosto de 2018, de https://doi.org/10.18616/ce.v0i0.2897.

Madeira, C. G., \& Gallucci, L. (2009). Mídias sociais, redes sociais e sua importância para as empresas no início do século XXI. Recuperado em Agosto, 2018, de http://www.intercom.org.br/ papers/nacionais/2009/resumos/R4-1163-1.pdf.

Michaelis (2018). Vítima. Recuperado em Agosto de 2018, de http://michaelis.uol.com.br/busca?i$\mathrm{d}=8 \mathrm{a} 0 \mathrm{~W} 5$.

Ministério da Saúde (2017). Suicídio: saber, agir e prevenir. [Online]. Brasília. Recuperado de http://portalarquivos2.saude.gov.br/images/ pdf/2017/setembro/20/Folheto-jornalistas-15x21cm.pdf.

Organização Mundial da Saúde. (2000). Prevenção do suicídio: um manual para a mídia. Genebra: Organização Mundial da Saúde.

Pompeia, J. A., \& Sapienza, B. T. (2004). Na presença do sentido: uma aproximação fenomenológica a questões existenciais básicas. São Paulo: EDUC; Paulus.

Portal Agreste Em Alerta. (2017, Dezembro 27). Jovem comete suicídio nesta quarta-feira 27/12 na Cohab II em Garanhuns/PE. Recuperado em Junho de 2018, de http://www.agresteemalerta. com.br/2017/12/jovem-comete-suicidio-nesta-quarta_27.html.

Queiroz, A. (2018). Prevenção do suicídio, técnica e psicologia fenomenológico existencial. In A. M. L. C. de Feijoo (Org.). Suicídio: entre o morrer e $o$ viver (pp. 195-212). Rio de Janeiro: IFEN. 
Santos, S. (2003). Elaboração de Projeto. Documento não publicado, Universidade de Pernambuco Bacharelado em Psicologia - Formação de Psicólogo, Garanhuns.

Santos, S. (2016). Conversando sobre a metodologia na pesquisa fenomenológica existencial. Documento não publicado, Universidade de Pernambuco - Bacharelado em Psicologia - Formação de Psicólogo, Garanhuns.

Sá-Silva, J. R., Almeida C. D., \& Guindani, J. F. Pesquisa documental: pistas teóricas e metodológicas. Rev. Bras. Hist. Cienc. Soc., 1(1), 1-15. Recuperado em Maio de 2018, de https://www. rbhcs.com/rbhcs/article/view/6.

Silva, E. F. G., \& Santos, S. E. B. (2017). Fenomenologia existencial como um caminho para pesquisa qualitativa em Psicologia. Revista Nufen 9(3), 110-116.

Silva, V. (2018). Um projeto de uma outra compreensão acerca do suicídio. Em A. M. L. C. de Feijoo (Org.). Suicídio: entre o morrer e o viver (pp. 7-16). Rio de Janeiro: IFEN.

V\&C Garanhuns. (2017, Julho 27). Usou a própria pistola: Policial civil comete suicídio na Vila do Quartel em Garanhuns. Recuperado em Junho de 2018, de http://www.vecgaranhuns. com/2017/07/usou-propria-pistola-policial-civil.html.
World Health Organization (2017). Preventing suicide: a resource for media professionals, Update 2017. Geneva: WHO. Recuperado de http://apps. who.int/iris/bitstream/handle/10665/258814/ WHO-MSD-MER-1 7.5-eng.pdf;jsessioni$\mathrm{d}=$ 82A30CFF9E3CFF320E26B4805BB665F0?sequence $=1$.

Débora Victor Aragão Alves (orcid.org/0000-00016249-7487), Universidade de Pernambuco. Endereço: Rua Luiz Barbalho, 167, apt. 402 - Boa Vista, Recife - PE. CEP: 50030-230 Email: deboravictoraragao@ outlook.com

Suely Emilia de Barros Santos (orcid.org/0000-00030022-201X), Universidade de Pernambuco. Email: suely.emilia@upe.br 